\title{
Co-evolution of xylem water and soil water stable isotopic composition in a northern mixed forest biome
}

\author{
Jenna R. Snelgrove ${ }^{1}$, James M. Buttle ${ }^{2}$, Matthew J. Kohn ${ }^{3}$, and Dörthe Tetzlaff ${ }^{4,5}$ \\ ${ }^{1}$ Environmental and Life Sciences Graduate Program, Trent University, Peterborough, ON, K9L 0G2, Canada \\ ${ }^{2}$ School of the Environment, Trent University, Peterborough, ON, K9L 0G2, Canada \\ ${ }^{3}$ Department of Geoscience, Boise State University, ID 83725-1535, USA \\ ${ }^{4}$ Leibniz Institute of Freshwater Ecology and Inland Fisheries (IGB), Berlin, Germany \\ ${ }^{5}$ Department of Geography, Humboldt University Berlin, Berlin, Germany
}

Correspondence: James M. Buttle (jbuttle@trentu.ca)

Received: 13 November 2020 - Discussion started: 24 November 2020

Revised: 17 March 2021 - Accepted: 18 March 2021 - Published: 21 April 2021

\begin{abstract}
Plant-soil water isotopic dynamics in northern forests have been understudied relative to other forest types; nevertheless, such information can provide insight into how such forests may respond to hydroclimatic change. This study examines the co-evolution of xylem water and soil water stable isotopic compositions in a northern mixed forest in Ontario, Canada. Gross precipitation, bulk soil water and xylem water were sampled from pre-leaf out to postsenescence in 2016 for eastern white cedar, eastern hemlock, red oak and eastern white pine. Near-bole soil water contents and mobile soil water isotopic compositions were measured for the last three species. Mobile soil water did not deviate significantly from the local meteoric water line (LMWL). In contrast, near-surface bulk soil water showed significant evaporative enrichment relative to the LMWL from pre-leaf out to peak leaf out under all tree canopies, while xylem water was significantly depleted in ${ }^{18} \mathrm{O}$ and particularly ${ }^{2} \mathrm{H}$ relative to bulk soil water throughout the growing season. Inter-species differences in deviation of xylem water from the LMWL and their temporal changes emerged during the growing season, with coniferous species xylem water becoming isotopically enriched, while that of red oak became more depleted in ${ }^{2} \mathrm{H}$ and ${ }^{18} \mathrm{O}$. These divergences occurred despite thin soil cover (generally $<0.5 \mathrm{~m}$ depth to bedrock) which would constrain inter-species differences in tree rooting depths in this landscape. Isotopic fractionation at the tree root and fractionation of xylem water via evaporation through the tree bark are among the most plausible potential explanations for deviations between xylem and soil wa-
\end{abstract}

ter isotopic compositions. Differences in the timing and intensity of water use between deciduous and coniferous trees may account for inter-specific variations in xylem water isotopic composition and its temporal evolution during the growing season in this northern forest landscape.

\section{Introduction}

Northern forest landscapes are highly sensitive to climate change (Laudon et al., 2017; Sprenger et al., 2018a) and may experience marked hydrological shifts in the future, such as changes in the amount, form and timing of precipitation (Carey et al., 2010; Hartmann et al., 2013) as well as increases in drought frequency and intensity (Brinkmann et al., 2019). Alterations in snow accumulation and ablation have important implications for soil water availability to plants at the start of the growing season (Smith et al., 2011; Carey et al., 2013), and vegetation in northern landscapes can exhibit rapid responses to such changes (e.g. Myers-Smith et al., 2019). Understanding how northern forests may respond to these anticipated hydrological changes would benefit from greater knowledge of the sources of water taken up by major tree species in these landscapes (Guswa et al., 2020). Environmental isotopes have often been used to study water use by vegetation (e.g. Evaristo et al., 2015), and efforts to account for the isotopic composition of plant water in relation to that of major water pools in forest landscapes has led to the ecohydrological separation or "two water worlds" hypothesis 
(Brooks et al., 2010; McDonnell, 2014). This hypothesis proposes that a highly mobile pool of soil water similar in isotopic composition to precipitation contributes to groundwater and streamflow, while a less mobile pool of evaporatively enriched soil water supplies plant transpiration (Goldsmith et al., 2012; Knighton et al., 2019; Sprenger and Allen, 2020).

The review of the ecohydrological separation hypothesis by McCutcheon et al. (2017) presented three assumptions that must be met for the hypothesis to be supported:

1. There is a distinct difference between the isotopic composition of water taken up by plant roots and the water that drains through the soil profile.

2. This difference can be linked to isotopically distinct soil water sources.

3. These isotopically distinct soil water sources arise from differences in soil water mobility.

Studies have called one or more of these assumptions into question, such as the assumption that mobile and tightly retained subsurface waters are independent water pools (Sprenger et al., 2018b), and there is mounting evidence that the two water worlds hypothesis is overly simplistic (Penna et al., 2018). For example, Bowling et al. (2017) noted that the assumption that plants extract more strongly held soil water in the presence of less strongly retained soil water near the plant roots violates current physiological understanding of how plants take up water, which is primarily driven by a potential gradient between the soil and the plant leaf or needle.

Nevertheless, the interface between soils and plants represents the potential source of novel advances in process understanding in ecohydrology, and systematic assessments of plant-soil water isotopic dynamics need to be examined across distinct soil types and vegetation structures (Dubbert and Werner, 2019). There is a particular need to examine relationships between the isotopic composition of xylem water in relation to that of potential source waters in northern forests (Tetzlaff et al., 2015; Penna et al., 2018), since much previous research into water use by vegetation using environmental isotopes has focused on tropical, seasonally dry or arid regions (Evaristo et al., 2015; Gaines et al., 2016). Most ecohydrological separation studies have also been restricted to the growing season (Liu et al., 2020), and greater consideration should be paid to the full seasonal variability of soil and plant water isotopic composition (McCutcheon et al., 2017; Sprenger et al., 2018a; Tetzlaff et al., 2021). This variability in northern landscapes is driven in part by a pronounced annual cycle that ranges from isotopically depleted snowfall to isotopically enriched summer rainfall (Birks and Gibson, 2009), with important implications for the isotopic composition of source water available for plant uptake at the start of the growing season (McCutcheon et al., 2017; Allen et al., 2019). Plant-soil water isotopic dynamics may also differ between tree species in northern landscapes. Trees cannot be treated as "simple transport vessels, or straws" (Evaristo et al., 2019, p. 18), and inter-specific differences in the interplay between rooting depth and architecture and water flow paths and storage in the soil profile may manifest themselves in the resulting isotopic composition of plant water uptake (Geris et al., 2015; Allen et al., 2019).

The purpose of this study is to examine the co-evolution of the isotopic composition of xylem water and soil water from pre-leaf out to post-senescence for some common tree species in Canada's northern forest landscapes. We address the following questions:

1. What are the temporal changes in the isotopic composition of soil water and xylem water throughout the complete growing season in a northern forest landscape, and do the trajectories of such changes differ between tree species?

2. What are the potential drivers of any inter-specific differences in the deviation of the isotopic composition of xylem water from that of soil water?

Answering these questions may improve our understanding of relationships between soil water and water taken up for transpiration by different tree species in northern forests and provide insight into how these species may respond to hydroclimatic change in northern landscapes.

\section{Study area and methods}

\subsection{Study area}

The study was conducted in the Plastic-1 (PC-1; 23.3 ha) sub-catchment of Plastic Lake (Fig. 1) on the southern edge of the Canadian Shield near Dorset, Ontario, Canada $\left(45^{\circ} 11^{\prime} \mathrm{N}, 78^{\circ} 50^{\prime} \mathrm{W}\right)$. Pleistocene glacial till overlies Precambrian metamorphic silicate bedrock (Wels et al., 1990), and thin soil cover is formed from sandy basal tills, with an average depth of $\sim 0.4 \mathrm{~m}$ to bedrock (Neary et al., 1987; Watmough et al., 2007). Visual observations of outcrops in PC-1 suggest the bedrock is relatively unfractured. Soils are overlain with a $\sim 5 \mathrm{~cm}$ thick LFH (litter, fermented, humic) layer (Neary et al., 1987) and are sandy with minor clay and low organic matter contents, showing little decline with depth (Buttle and House, 1997). Forest cover is largely coniferous and dominated by red oak (Quercus rubra, Or), eastern white pine (Pinus strobus, $\mathrm{Pw}$ ), eastern hemlock (Tsuga canadensis, He), white cedar (Thuja occidentalis, Ce) and black spruce (Picea mariana). The latter is confined to a wetland occupying the central portion of PC-1. Leaf out of Or is in mid-May, while senescence occurs by early October. A meteorological station $\sim 500 \mathrm{~m}$ from the study site (Fig. 1) operated by the Dorset Environmental Science Centre (DESC) provides temperature and precipitation data. Daily average temperatures range between -10 and $18^{\circ} \mathrm{C}$ throughout the year, based on meteorological station data between 1981 


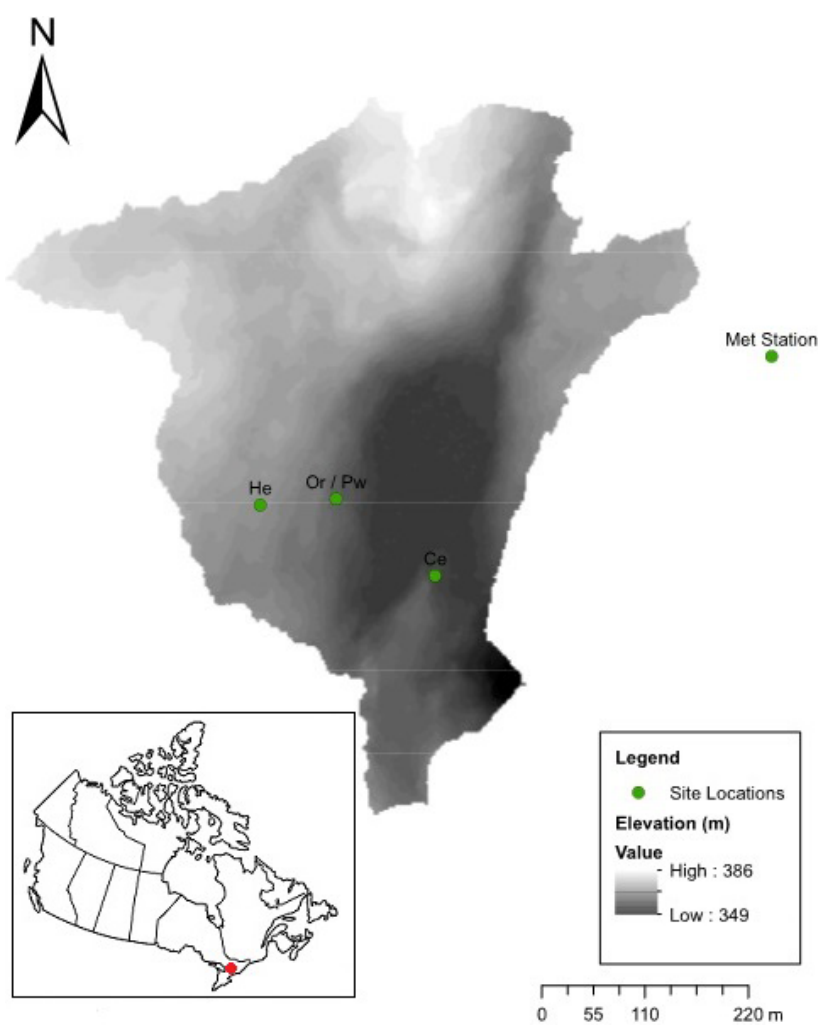

Figure 1. Digital elevation model of the PC-1 catchment, showing the location of trees sampled for xylem water and bulk soil water (Ce - eastern white cedar, $\mathrm{He}$ - eastern hemlock, Or - red oak, Pw - eastern white pine) and the meteorological station.

and 2010. Mean annual precipitation is $\sim 799 \mathrm{~mm} \mathrm{yr}^{-1}$ of rain and $\sim 260 \mathrm{~mm} \mathrm{yr}^{-1}$ of snow water equivalent.

\subsection{Gross rainfall sampling and potential evapotranspiration estimation}

Gross precipitation $\left(P_{\mathrm{g}}\right)$ was measured weekly for amount and isotopic composition from 27 May to 21 October 2016 using a bulk collector at the meteorological station which minimised isotopic fractionation via air exchange with the external environment by reducing the water surface exposed to the atmosphere (Gröning et al., 2012). Snowmelt samples were obtained from a snowmelt runoff plot at Paint Lake, $\sim 12 \mathrm{~km}$ northwest of PC-1 (Lane et al., 2020). Daily potential evapotranspiration (PET) values were taken from Sprenger et al. (2018a), based on meteorological station data and the Penman-Monteith equation (Allen et al., 1998).

\subsection{Xylem water sampling}

Four tree species in PC1 were selected to conduct xylem water sampling: $\mathrm{Ce}, \mathrm{He}$, Or and Pw. Five mature trees with similar diameter at breast heights (DBHs) were chosen for each species (Table 1). Sampled Or and Pw trees were inter-
Table 1. Tree height $(\mathrm{m})$, diameter at breast height $(\mathrm{DBH})(\mathrm{cm})$ and projected crown area (PCA) $\left(\mathrm{m}^{2}\right)$ for all eastern white cedar (Ce), eastern hemlock $(\mathrm{He})$, red oak (Or) and eastern white pine $(\mathrm{Pw})$ trees sampled for bulk soil water, xylem water, soil water content and mobile soil water. Soil surrounding trees indicated in italics was sampled for soil water content and mobile soil water as reported in Snelgrove et al. (2019).

\begin{tabular}{lccc}
\hline $\begin{array}{l}\text { Sampling } \\
\text { tree }\end{array}$ & $\begin{array}{c}\text { Height } \\
(\mathrm{m})\end{array}$ & $\begin{array}{c}\text { DBH } \\
(\mathrm{cm})\end{array}$ & $\begin{array}{c}\text { PCA } \\
\left(\mathrm{m}^{2}\right)\end{array}$ \\
\hline $\mathrm{Ce}-01$ & 11.2 & 22.6 & 9.1 \\
$\mathrm{Ce}-02$ & 10.9 & 25.5 & 9.1 \\
$\mathrm{Ce}-03$ & 11.5 & 25.1 & 10.5 \\
$\mathrm{Ce}-04$ & 8.5 & 21.3 & 7.8 \\
$\mathrm{Ce}-05$ & 11.1 & 26.6 & 8.6 \\
$\mathrm{He}-01$ & 17.5 & 34.1 & 39.0 \\
$\mathrm{He}-02$ & 13.5 & 40.4 & 87.4 \\
$\mathrm{He}-03$ & 18.5 & 41.2 & 62.2 \\
$\mathrm{He}-04$ & 17.8 & 35.2 & 63.6 \\
$\mathrm{He}-05$ & 16.9 & 39.5 & 70.9 \\
Or-01 & 22.3 & 50.6 & 21.4 \\
Or-02 & 20.5 & 59.5 & 44.8 \\
Or-03 & 17.8 & 66.5 & 107.5 \\
Or-04 & 13.6 & 50.8 & 75.4 \\
Or-05 & 19.4 & 57.9 & 111.2 \\
Pw-01 & 17.6 & 60.5 & 21.0 \\
Pw-02 & 30.1 & 62.4 & 12.7 \\
Pw-03 & 26.8 & 53.2 & 78.5 \\
Pw-04 & 31.2 & 51.2 & 52.2 \\
Pw-05 & 20.3 & 47.4 & 25.1 \\
\hline
\end{tabular}

mixed, while $\mathrm{He}$ trees were $\sim 100 \mathrm{~m}$ away from the $\mathrm{Or} / \mathrm{Pw}$ stand, and Ce trees were $\sim 200 \mathrm{~m}$ from the He trees and $\sim$ $130 \mathrm{~m}$ from the Or/Pw stand (Fig. 1). Xylem water was sampled six times between October 2015 and November 2016, including post-senescence 2015 (26 October to 3 November 2015), pre-leaf out 2016 (26 to 29 April 2016), postleaf-out 2016 (20 to 22 June 2016), peak-leaf out 2016 (8 to 10 August 2016), pre-senescence 2016 (23 to 24 September 2016) and post-senescence 2016 ( 2 to 4 November 2016). Xylem cores were extracted from each tree at breast height using an increment borer (3-thread, $5.15 \mathrm{~mm}$ core). Cores were extracted a few centimetres above or below the preceding core. Bark was removed from retrieved cores, which were immediately stored in $200 \mathrm{~mL}$ glass scintillation vials with zero headspace. These were taped, sealed with Parafilm and stored in a freezer to prevent exchange with the atmosphere. Elapsed time between core extraction and storage in the sealed vials was on the order of $1 \mathrm{~min}$.

\subsection{Soil water isotopic sampling and soil water content}

Bulk soil samples were obtained concurrent with xylem water sampling in a randomised direction $1 \mathrm{~m}$ from the bole of each tree sampled for xylem water. Following litter layer re- 
moval, a minimum of $40 \mathrm{~g}$ of soil was collected using an auger at $5 \mathrm{~cm}$ depth increments until bedrock was reached. An average of six samples was obtained at a given tree, ranging from 1 to 16 samples. Samples were double-bagged in Ziploc bags while minimising any stored air and stored at $4^{\circ} \mathrm{C}$ prior to analysis. Samples were stored for no more than 2 weeks prior to analysis, and Hendry et al. (2015) indicated that any water losses and resulting changes in soil water isotopic content for these short storage periods would be negligible. This bulk soil water was assumed to represent all water stored within the soil, including both mobile and more tightly held soil water.

Mobile soil water was sampled from tension lysimeters installed at 0.1 and $0.4 \mathrm{~m}$ depths at 0.1 and $1 \mathrm{~m}$ from the tree bole in a randomised direction for three $\mathrm{He}$, three Or and three Pw trees sampled for xylem water (Snelgrove et al., 2019). Tension lysimeters were manufactured using Soil Test $^{\mathrm{TM}} 2$ bar ceramic cups and PVC tubing. Tension lysimeters were sampled weekly between 2 June and 21 October 2016 and reset to a minimum negative air pressure of $60 \mathrm{kPa}$ using a hand pump. Samples were stored in sealed glass vials with zero headspace at $4{ }^{\circ} \mathrm{C}$ prior to isotopic analysis.

Soil water content (SWC) was measured at two ATL-1 access tubes (http://www.delta-t.co.uk, last access: 30 May 2019) installed 0.1 and $1 \mathrm{~m}$ from the bole of each of the three trees of a given species sampled for mobile soil water. Tubes were installed in a randomised direction from the bole. Measurements were concurrent with tension lysimeter sampling. A Delta T PR2/6 Soil Moisture Profile Probe ${ }^{\mathrm{TM}}$ measured SWC at each access tubes at 0.1, 0.2, 0.3 and $0.4 \mathrm{~m}$ depths. Measurements at each depth were made three times per access tube and averaged to obtain mean SWC at each depth. These values were used to estimate the total depth of water held in the upper $0.5 \mathrm{~m}$ of soil as described in Snelgrove et al. (2019).

\subsection{Isotopic analyses}

All isotope ratios are expressed relative to Vienna Standard Mean Ocean Water-Standard Light Antarctic Precipitation (VSMOW-SLAP; Coplen et al., 2002) using standard per mil $(\% o)$ notation. Tree core samples were analysed at the Boise State University Stable Isotope Laboratory. Xylem water was obtained from the cores by cryogenic extraction, followed by mass spectrometry using a Thermo Delta $\mathrm{V}$ isotope ratio mass spectrometer (IRMS) coupled with a Thermo temperature conversion elemental analyser (TC/EA) configured for water injection analyses (Koeniger et al., 2011), with a precision of $\pm 1.0 \%$ o for $\delta^{2} \mathrm{H}$ and $\pm 0.1 \%$ o for $\delta^{18} \mathrm{O}$. An extreme maximum limit on external reproducibility can be estimated from the compositional consistency among analyses of the same species on a single sampling date (e.g., all Or data on 26 April 2016, etc.). This limit is a maximum because different trees are expected to have different compositions.
The mean and median reproducibilities for these data are $\sim 10 \%$ in $\delta^{2} \mathrm{H}$ and $\sim 1 \%$ in $\delta^{18} \mathrm{O}$. Bulk soil water, tension lysimeter and $P_{\mathrm{g}}$ samples were analysed at the University of Saskatchewan using Los Gatos Research liquid water offaxis integrated-cavity output spectroscopy (off-axis ICOS) with a precision of $\leq \pm 1.0 \%$ o for $\delta^{2} \mathrm{H}$ and $\pm 0.2 \%$ o for $\delta^{18} \mathrm{O}$. The ICOS instrument at the University of Saskatchewan was cross-correlated with the IRMS at Boise State University. Bulk soil samples were analysed using vapour extraction of water in an equilibrium state from the sealed Ziploc bags. We are aware that different methods of soil water extraction have been a major focus of research in the past few years, with no definitive agreement on a standard method (e.g. AraguásAraguás et al., 1995; Orlowski et al., 2016, 2018). Previous work has shown the direct equilibrium method to give similar results to those from cryogenic extraction for sandy soils with low organic matter contents such as those at PC1 (Sprenger et al., 2018a, b). The accuracy of the direct water-vapour equilibration method was $\pm 0.3 \%$ for $\delta^{18} \mathrm{O}$ and $\pm 1.1 \%$ o for $\delta^{2} \mathrm{H}$. For a detailed description of the procedure, we refer to Sprenger et al. (2018a). Snowmelt samples were analysed at the University of Toronto using a Los Gatos Research DLT-100 liquid water isotope analyser with a precision of $\leq \pm 1.0 \%$ ofor $\delta^{2} \mathrm{H}$ and $\pm 0.12 \%$ ofor $\delta^{18} \mathrm{O}$.

The local meteoric water line (LMWL) was determined by regressing $\delta^{2} \mathrm{H}$ on $\delta^{18} \mathrm{O}$ for all snowmelt and $P_{\mathrm{g}}$ samples (Klaus et al., 2015). Isotopic compositions of soil water and xylem water samples were compared with the LMWL using the line-conditioned excess (lc-excess), which defines the degree of deviation from the LMWL using

lc-excess $=\delta^{2} \mathrm{H}-a \times \delta^{18} \mathrm{O}-b$,

where $a$ and $b$ are the LMWL's slope and intercept, respectively (Landwehr and Coplen, 2006). Negative lc-excess indicates evaporative enrichment relative to the LMWL (Landwehr and Coplen, 2006). McCutcheon et al. (2017) noted the benefit of lc-excess values in showing "isotopic distinction" between two water samples. These may differ markedly in their $\delta \mathrm{D}$ and $\delta^{18} \mathrm{O}$ values but can be considered genetically similar if they both plot on the LMWL.

\subsection{Statistics}

All statistical analyses were performed using the stats package in R Statistical Software (R Core Team, 2019). ShapiroWilks tests were used to assess normality of xylem water lc-excess values for each sampling period and species. Oneway analysis of variance (ANOVA) was used to compare differences in xylem water lc-excess between sampling periods for each tree species. Levene's test confirmed homogeneity of variances. Tukey's honest significant difference (HSD) tests identified significant differences in the data for each tree species. Inter-specific differences in xylem water lc-excess for a given sampling period were assessed using $t$ tests (unequal variances, Bonferroni-corrected). Successive 
sampling of the same trees meant that the isotopic composition of xylem water on a given sampling date was partly dependent on that from the previous sampling. Nevertheless, our approach allowed us to examine the temporal trajectory of xylem water for each of the sampled trees. We feel this is preferable to deriving this trajectory by sampling different trees at different times, which could be influenced by intertree differences in xylem water isotopic composition on a given sampling date.

\section{Results}

\subsection{Hydrometeorological conditions during the sampling period}

Precipitation data for the PC-1 meteorological station were not available for the fall 2015 period. Total precipitation at the station for 1 January to 31 October $2016(957 \mathrm{~mm})$ exceeded the 30-year normal precipitation for January to October $(854 \mathrm{~mm})$ at the nearby Dorset MOE climate station (station ID 6112072). This was the result of above-average precipitation (largely as snow) in February and March and a wetter than normal August ( $173 \mathrm{~mm}$ per month vs. $76 \mathrm{~mm}$ per month). Conversely, September 2016 was much drier than normal $(47 \mathrm{~mm}$ per month vs. $114 \mathrm{~mm}$ per month). Daily PET ranged from 1 to $6.8 \mathrm{~mm} \mathrm{~d}^{-1}$, peaking in mid-June and declining in late October. Total PET from 27 May to 21 October 2016 was $597 \mathrm{~mm}$, while total $P_{\mathrm{g}}$ for the same period was $440 \mathrm{~mm}$. The Canadian Drought Monitor (https://www.agr. gc.ca/atlas/maps_cartes/canadianDroughtMonitor/, last access: 18 June 2020) indicated that the April-October 2016 growing season was relatively dry, with conditions ranging from abnormally dry (April) through to moderate (July to October) and severe drought (June).

\subsection{Soil water contents}

Total water depth in the upper $0.5 \mathrm{~m}$ of soil at 0.1 and $1 \mathrm{~m}$ from $\mathrm{He}$, Or and $\mathrm{Pw}$ tree boles showed similar trends from early June to late October 2016 (Fig. A1): gradual draining through June into early August, a marked increase following $123 \mathrm{~mm}$ of rain between 9 and 17 August and relatively high SWCs until the end of monitoring (see Snelgrove et al., 2019, for greater detail). SWCs were similar at 0.1 and $1 \mathrm{~m}$ from the boles of trees of a given species. Greatest variability in SWC was seen around Or trees, while the least was around He trees.

\subsection{Isotope results}

\subsubsection{Precipitation}

Figure 2a shows dual isotope plots of snowmelt and rainfall separated into periods prior to bulk soil water and xylem water sampling. Snowmelt samples represented pre-leaf out values, which were depleted in ${ }^{2} \mathrm{H}$ and ${ }^{18} \mathrm{O}$ relative to rainfall for the other periods; however, there was considerable overlap in rainfall isotopic composition with no clear demarcation between sampling periods. The local meteoric water line (LMWL) using all samples was

$\delta^{2} \mathrm{H}=7.0395 \cdot \delta^{18} \mathrm{O}+4.6032 ; \quad R^{2}=0.97$.

Most throughfall and stemflow samples for $\mathrm{He}$, Or and Pw trees fell on the LMWL, indicating limited isotopic enrichment of $P_{\mathrm{g}}$ as it passed through the forest canopy (Snelgrove et al., 2019).

\subsubsection{Mobile and bulk soil water}

Mobile soil water fell on the LMWL (Fig. 2b), particularly deeper samples and those taken post-senescence in 2015 and 2016. Snelgrove et al. (2019) also found limited evaporative enrichment of mobile soil water and weak correspondence between isotopic composition of mobile soil water and that of $P_{\mathrm{g}}$, throughfall or stemflow inputs to the soil.

Most bulk soil water samples also plotted along the LMWL. However, the best-fit line of $\delta^{2} \mathrm{H}$ vs. $\delta^{18} \mathrm{O}$ for bulk soil water had a slope of 5.3, shallower than for meteoric water (7.0; Eq. 2), indicating evaporative enrichment of some samples. Enrichment was most pronounced at peak leaf out (Fig. 2c). It is important to note the poor agreement between bulk soil water and mobile soil water lc-excess sampled within $2 \mathrm{~d}$ or less of one another for a given tree species (Fig. 2d). Bulk soil water tended to be evaporatively enriched (more negative lc-excess) relative to mobile soil water sampled on or close to the same day.

Bulk soil water lc-excess values showed broadly similar distributions with depth beneath all tree species (Fig. 3). Post-senescence 2015 samples showed considerable variability at a given depth and no obvious trends with depth, with a tendency for negative lc-excess values for all tree species. Lc-excess at all depths became more positive at pre-leaf out in late April, which may reflect large preceding inputs of snowmelt water which flushed the soil profile. Lc-excess was more negative at post-leaf out in late June, indicating evaporative enrichment. This was least pronounced for Pw relative to the other species. All species showed negative lc-excess for near-surface bulk soil water and increasing values with depth at peak leaf out in early August. Lc-excess approached or equalled 0 at pre-senescence sampling in late September, consistent with decreased evaporation (Snelgrove et al., 2019). Lc-excess values at post-senescence 2016 were similar to those at post-senescence 2015 for Ce; however, 2016 values were generally more positive than 2015 values for $\mathrm{He}$, Or and Pw.

\subsubsection{Xylem water}

Xylem water isotopic composition changed during the growing season, with the trajectory of this change differing be- 

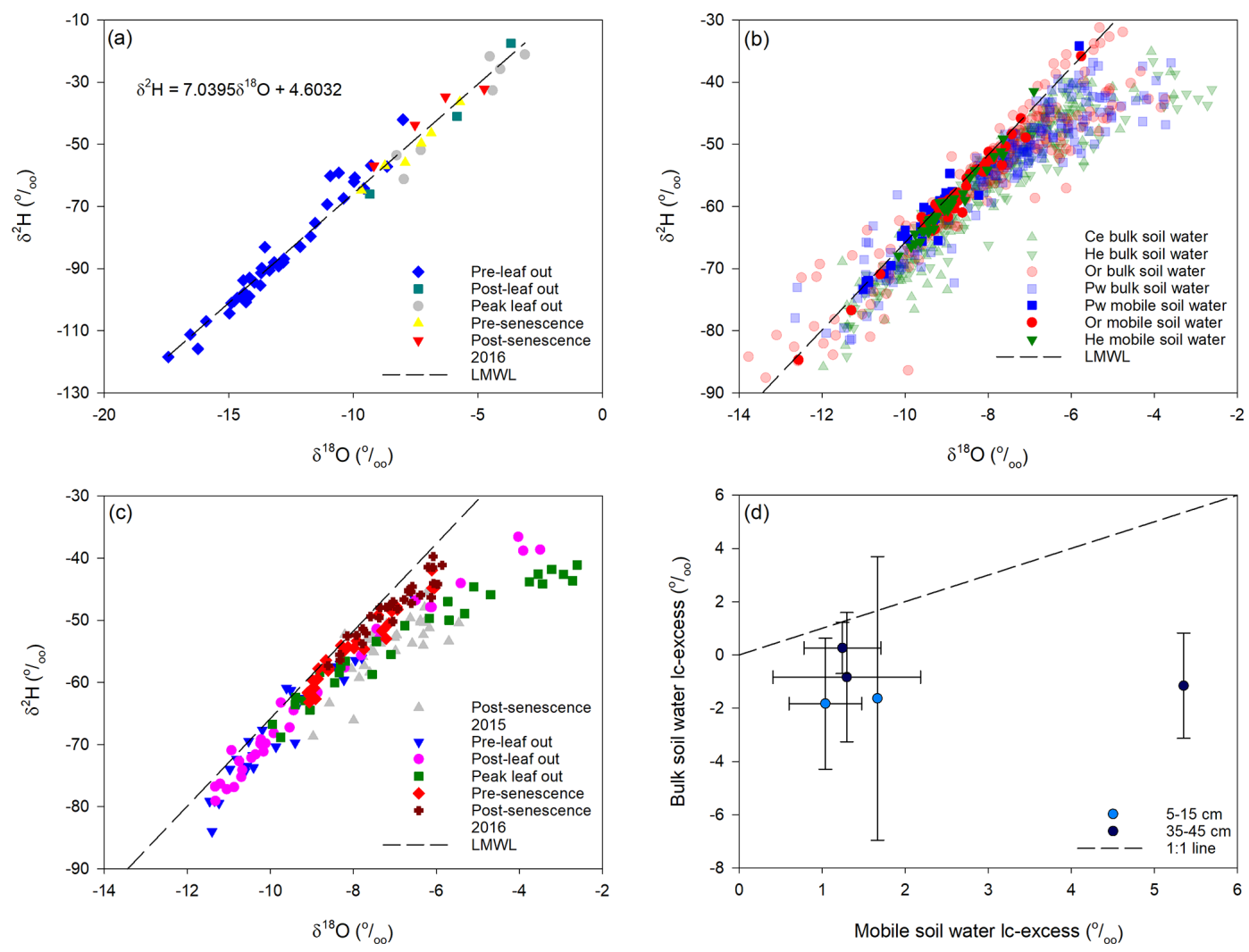

Figure 2. Isotopic composition of snowmelt and rainfall for the various sampling periods for xylem water and bulk soil water and the estimated local meteoric water line (LMWL) (a); isotopic composition of bulk soil water and mobile soil water for the sampled tree species (b); isotopic composition of bulk soil water for each sampling period beneath He trees (c); mean bulk soil water lc-excess at 5-15 and 35-45 cm depths ( $\pm 1 \mathrm{SD})$ vs. mobile soil water lc-excess at 10 and $40 \mathrm{~cm}$ depths, respectively, on or close to the same date (d).

tween species (Fig. 4). Coniferous species saw gradual enrichment of ${ }^{2} \mathrm{H}$ and ${ }^{18} \mathrm{O}$ from pre-leaf out to post-senescence in 2016. This transition was most pronounced for $\mathrm{Ce}$ and $\mathrm{Pw}$, while He saw greater overlap in isotopic compositions of post-leaf out, peak leaf and pre-senescence samples. Xylem water for Or had a different temporal trajectory: both ${ }^{2} \mathrm{H}$ and ${ }^{18} \mathrm{O}$ became depleted from pre-leaf out to peak leaf out, followed by slight depletion of ${ }^{2} \mathrm{H}$ from peak leaf out to presenescence and slight depletion of ${ }^{18} \mathrm{O}$ from pre-senescence to post-senescence 2016.

Inter-specific differences and temporal changes in xylem water isotopic composition at PC-1 exceeded inter-tree differences for a given species. Standard errors for xylem water for a given species and sampling date ranged from $0.39 \%$ to $5.13 \%$ or $\delta^{2} \mathrm{H}$ and $0.06 \%$ o to $0.79 \%$ or $\delta^{18} \mathrm{O}$ and were similar to previously reported results. Retzlaff et al. (2001) found insignificant differences in xylem water $\delta^{2} \mathrm{H}$ between trees of a given species on a given measurement date, with standard errors of $5 \%$ or less, while White and Smith (2015) found maximum standard errors for xylem water $\delta^{2} \mathrm{H}$ and $\delta^{18} \mathrm{O}$ of $5.49 \%$ and $0.84 \%$ for Acer negundo L. and $3.83 \%$ and $0.65 \%$ for Betula nigra $\mathrm{L}$.
Shaded areas in Fig. 4 represent the typical range in evaporation line slopes (2.5-5; Benettin et al., 2018) originating from the most depleted snowmelt sample $\left(\delta^{18} \mathrm{O}=-9.48 \%\right.$, $\delta^{2} \mathrm{H}=-118.10 \%$ o $)$ measured in spring 2016. These areas overlap most xylem water samples for Ce and $\mathrm{Pw}$ and many $\mathrm{He}$ and Or samples. Overlap with samples plotting above the steepest evaporation line slope is obtained by shifting the origin of the evaporation lines along the LMWL to less depleted snowmelt samples.

There was little overlap of xylem water and bulk soil water in dual isotope space (Fig. A2), with the former having much more negative $\delta^{2} \mathrm{H}$ and to a lesser extent $\delta^{18} \mathrm{O}$ relative to bulk soil water. There were pronounced inter-species differences in xylem-water lc-excess values and their relationship with near-surface soil water (Fig. 5). Bulk soil water lc-excess at $0-5 \mathrm{~cm}$ depth is shown, since near-surface soil experienced the greatest evaporative enrichment and thus the most negative lc-excess. Xylem water lc-excess values for a given sampling period and tree species were normally distributed. One-way ANOVA indicated no significant difference in xylem water lc-excess between sampling periods for He; conversely, other species showed significant differences between some sampling periods. There were no signif- 

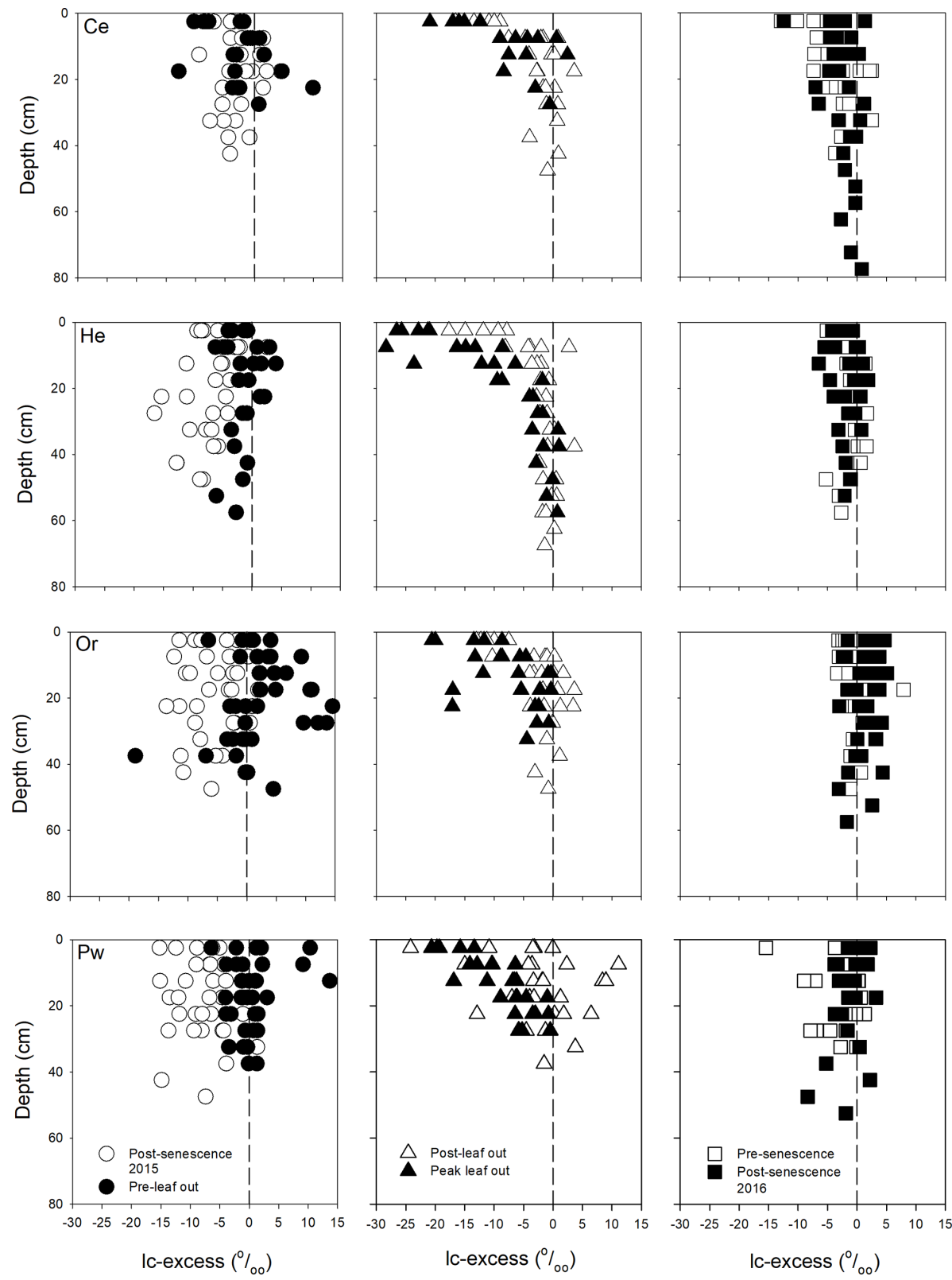

Figure 3. Bulk soil water lc-excess at different depths for the sampling periods for Ce (first row), He (second row), Or (third row) and $\mathrm{Pw}$ (fourth row). Vertical dashed line indicates a lc-excess of $0 \%$.

icant inter-species differences in xylem water lc-excess postsenescence 2015; however, distinctions emerged during subsequent sampling periods (Fig. 5, Table 2). Lc-excess for Or xylem water was less negative compared to other species and showed considerable overlap between sampling periods, with the most negative values at pre-senescence. Values also often overlapped near-surface soil water lc-excess. Lc-excess for He was similar for all sampling periods, although inter-tree variability declined progressively from pre-leaf out to presenescence. There was occasional overlap of xylem water and near-surface bulk soil water lc-excess values. A differ- ent relationship occurred for Ce and to a lesser extent Pw. Xylem water lc-excess for the former became more negative from post-senescence 2015 to peak leaf out and then became more positive. Lc-excess for Ce was generally more negative than for other species and was often more negative than the most evaporatively enriched bulk soil water. Lc-excess for Pw also declined from post-senescence 2015, becoming most negative at pre-senescence. Pw lc-excess also tended to fall outside the near-surface bulk soil water range, although there was more overlap than for Ce xylem water. 

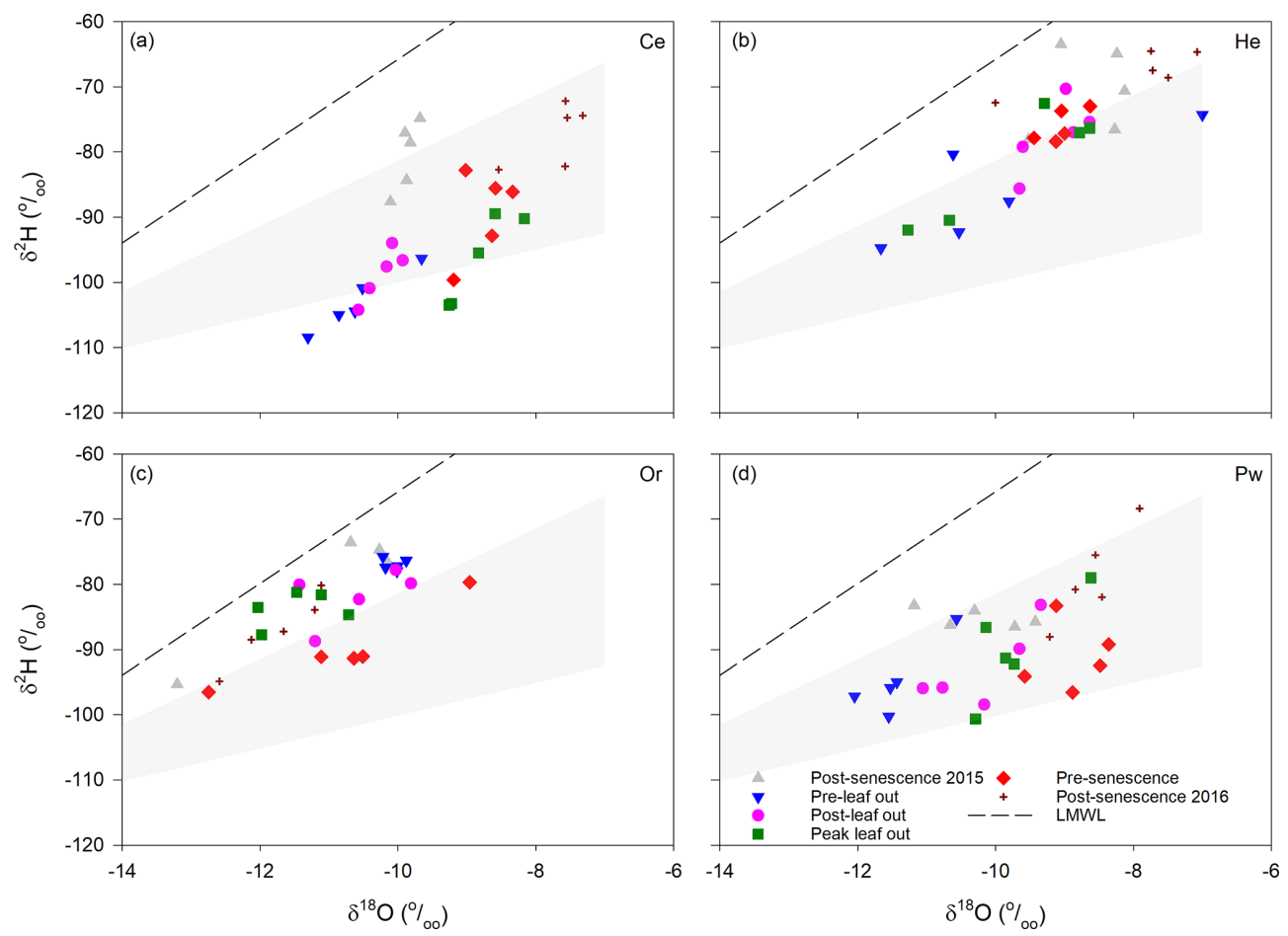

Figure 4. Xylem water isotopic composition for the different sampling periods for Ce (a), He (b), Or (c) and Pw (d). LMWL - local meteoric water line. Shaded areas encompass the range (2.5-5) of evaporation line slopes originating from the most isotopically depleted snowmelt sample measured in 2016.

Table 2. Significant differences in mean xylem water lc-excess for a given sampling period, determined from $t$ tests with $p=0.0015$ (equivalent to $p=0.05$ following Bonferroni correction).

\begin{tabular}{llllll}
\hline $\begin{array}{l}\text { Post- } \\
\text { senescence } \\
2015\end{array}$ & $\begin{array}{l}\text { Pre-leaf } \\
\text { out }\end{array}$ & $\begin{array}{l}\text { Post-leaf } \\
\text { out }\end{array}$ & $\begin{array}{l}\text { Peak leaf } \\
\text { out }\end{array}$ & $\begin{array}{l}\text { Pre- } \\
\text { senescence }\end{array}$ & $\begin{array}{l}\text { Post- } \\
\text { senescence } \\
2016\end{array}$ \\
\hline- & $\mathrm{Ce}<\mathrm{Or}$ & $\mathrm{Ce}<\mathrm{He}$ & $\mathrm{Ce}<\mathrm{He}$ & $\mathrm{Pw}<\mathrm{He}$ & $\mathrm{Ce}<\mathrm{Or}$ \\
& $\mathrm{Ce}<\mathrm{Pw}$ & $\mathrm{Ce}<\mathrm{Or}$ & $\mathrm{Ce}<\mathrm{Or}$ & & $\mathrm{Pw}<\mathrm{Or}$ \\
& $\mathrm{Pw}<\mathrm{Or}$ & $\mathrm{Pw}<\mathrm{Or}$ & $\mathrm{Ce}<\mathrm{Pw}$ & \\
& & & $\mathrm{He}<\mathrm{Or}$ & \\
& & & $\mathrm{Pw}<\mathrm{Or}$ & \\
\hline
\end{tabular}

Figure 6 presents soil water-xylem water offsets for $\delta^{2} \mathrm{H}$ throughout the study period, defined as the difference between the mean isotopic composition of soil water surrounding a sampled tree and xylem water for that tree. Offsets for $\delta^{18} \mathrm{O}$ showed similar patterns to those for $\delta^{2} \mathrm{H}$ and are not shown. Intra-species differences in $\delta^{2} \mathrm{H}$ offsets on a given sampling date could be appreciable; however, inter-tree differences for a given species between sampling times did not appear to be consistent. Temporal trajectories of these offsets showed inter-specific differences. Minimum offset values for Ce occurred at post-senescence in 2015. Values rose to maxima either at post-leaf out or peak leaf out before declining to post-senescence 2016. Offsets were more temporally constant for He with maxima at peak leaf out. There was a marked decline in the Or $\delta^{2} \mathrm{H}$ offsets from 2015 postsenescence to pre-leaf out, followed by a gradual increase to maxima at either pre-senescence or 2016 post-senescence. $\mathrm{Pw}$ had more temporally constant $\delta^{2} \mathrm{H}$ offsets with minima at either pre-leaf out or post-leaf out.

\section{Discussion}

\subsection{Temporal changes in the isotopic composition of soil water and xylem water in northern forests}

Bulk soil water isotopic composition exhibited similar trends between the different tree species' canopies. Near-surface bulk soil water showed evaporative enrichment at peak leaf 

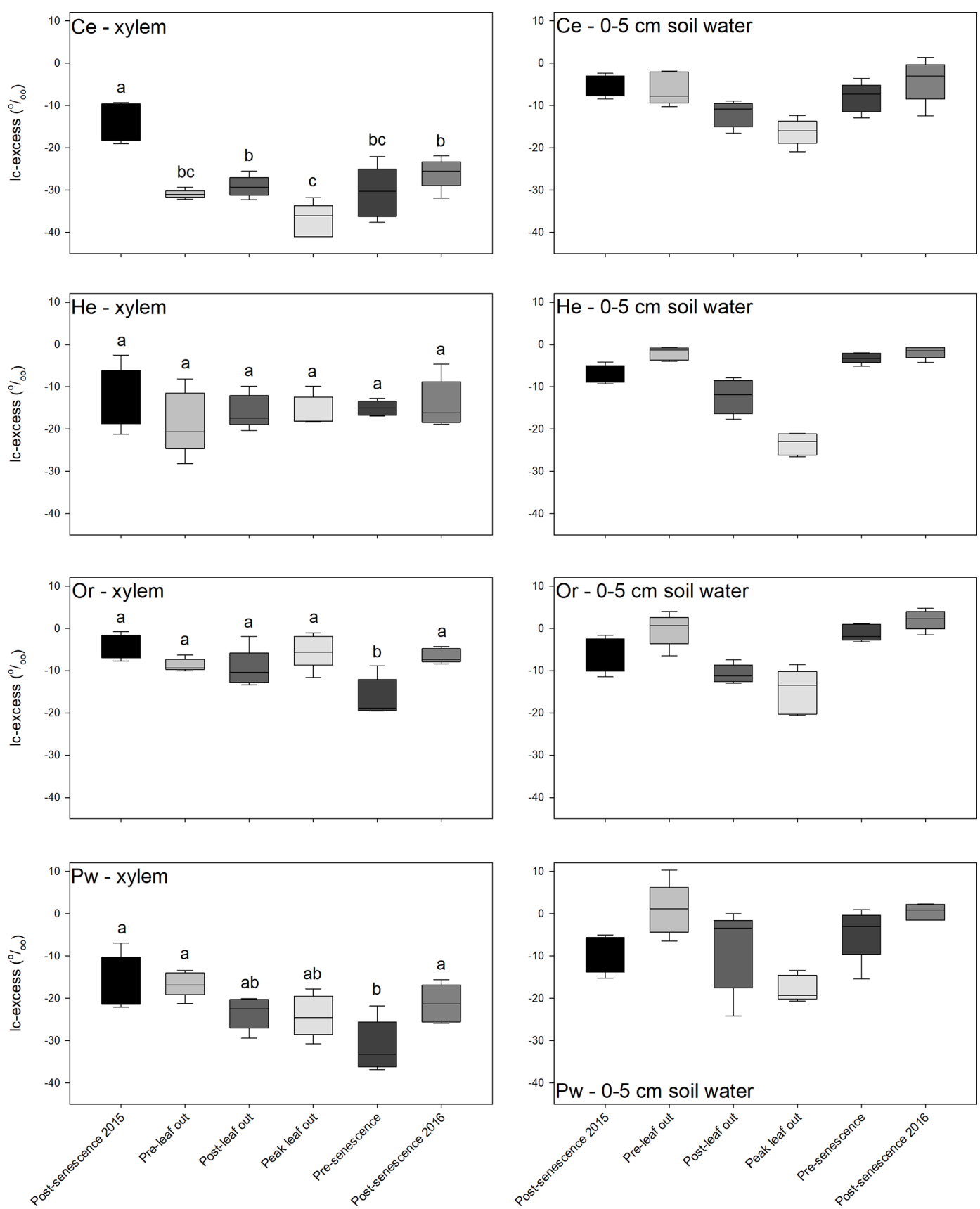

Figure 5. Box-and-whisker plots of xylem water (left-hand panels) and near-surface ( $0-5 \mathrm{~cm}$ depth) bulk soil water (right-hand panels) lcexcess values for Ce (first row), He (second row), Or (third row) and Pw (fourth row) for the different sampling periods. Horizontal line median, box - first to third quartiles, whiskers - maximum and minimum values. Xylem water box and whiskers with different letters for a given tree species are statistically different $(p=0.05)$ based on Tukey's HSD tests.

out, when SWCs reached a minimum (Figs. 3 and A1). Increased enrichment of bulk soil water relative to both the LMWL and corresponding mobile water with declining SWCs was also observed by Zhao et al. (2013) in a loamy soil and by Sprenger et al. (2018b) at PC-1. The bulk soil water slope in dual isotope space at PC-1 (5.3) agreed with values of 5.3 to 5.8 reported by Bowling et al. (2017) for riparian soils in eastern Utah, while lc-excess values for near-surface soils were within the range given in McCutcheon et al. (2017) for a semi-arid landscape in southwest Idaho. Bulk soil water isotopic composition following senescence did not return to that of the previous year for all tree species (Fig. 3). Brooks et al. (2010) also noted an inter-annual difference in soil wa- 

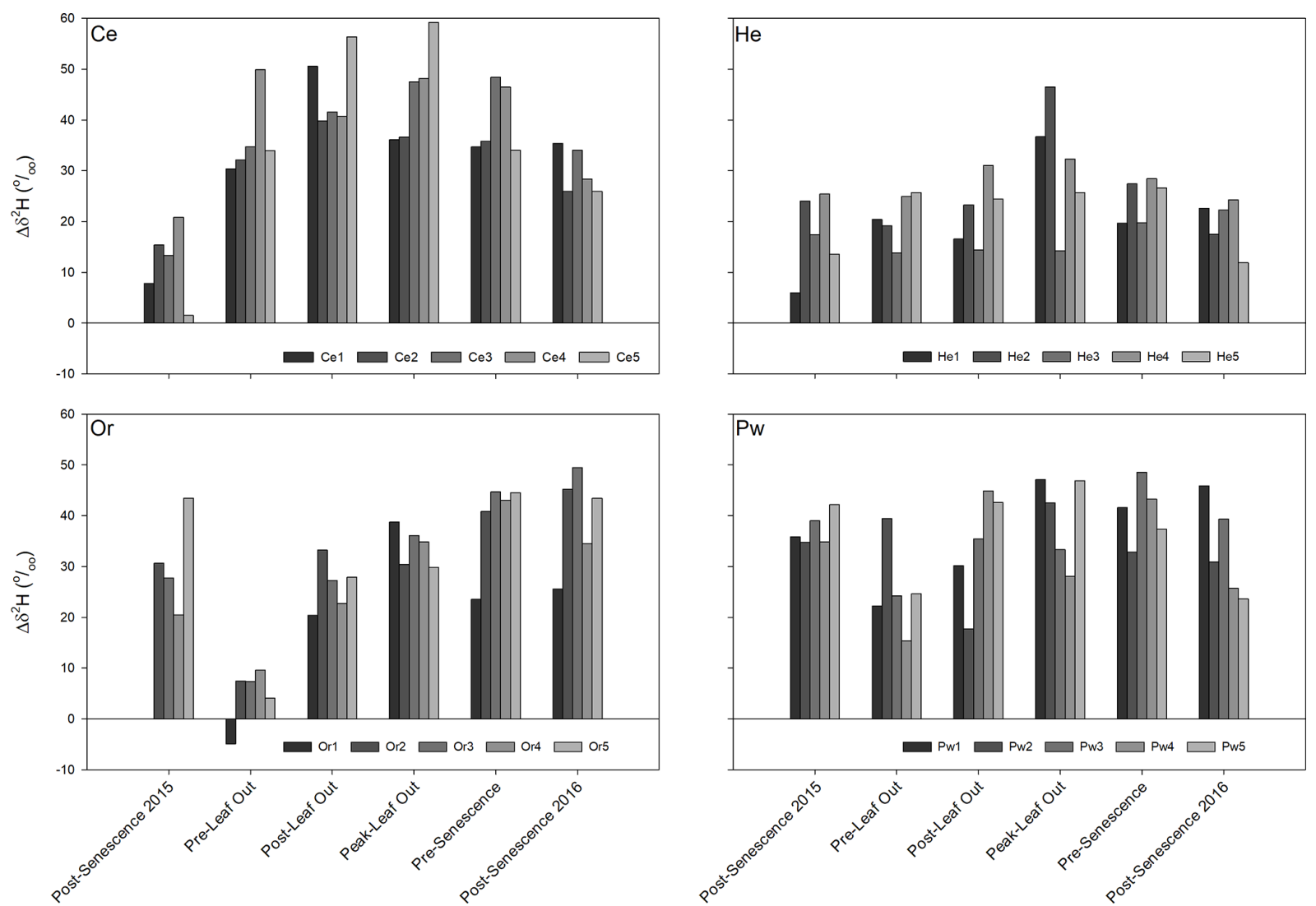

Figure 6. Bulk soil water-xylem water $\delta^{2} \mathrm{H}$ offsets $\left(\Delta \delta^{2} \mathrm{H}\right)$ for the sampled trees for each sampling period. See text for details on derivation of offsets. Positive values of $\Delta \delta^{2} \mathrm{H}$ indicate that xylem water $\delta^{2} \mathrm{H}$ is more negative than the corresponding mean bulk soil water $\delta^{2} \mathrm{H}$.

ter isotopic composition at the same location and depth for the same time of the year.

In contrast to similar trends in bulk soil water isotopic composition, xylem water showed intra- and inter-specific differences in its displacement from both bulk soil water and the LMWL and the temporal trajectory of that composition throughout the growing season. Distinctions between xylem water and bulk soil water isotopic compositions have been noted elsewhere. Brooks et al. (2010) found some plant water plotting beyond (and generally below) the range of soil water $\delta^{2} \mathrm{H}$ and $\delta^{18} \mathrm{O}$ in dual isotope space but did not address it, with Goldsmith et al. (2012) later suggesting this xylem water may have undergone further evaporation. Of the 17 isotope-based studies of plant water use in temperate forests (similar to the PC- 1 forest landscape) cited by Evaristo et al. (2015), 13 reported both soil water and xylem water offsets (analogous to lc-excess used here) and 4 indicated xylem water offsets falling below the range (i.e. were more negative) of the corresponding soil water offsets. More recent work (e.g. Geris et al., 2015; White and Smith, 2015; Bowling et al., 2017; Hervé-Fernández et al., 2016; McCutcheon et al., 2017; Brinkmann et al., 2019) also saw a distinction between the isotopic composition of xylem water and possible water sources that might support transpira- tion. Pronounced soil water-plant water $\delta^{2} \mathrm{H}$ offsets observed for all species at PC-1 (Fig. 6) may be a general occurrence in temperate forests (Barbeta et al., 2020). However, these values exceeded the mean $\delta^{2} \mathrm{H}$ offset of $10.6 \pm 3.05 \%$ oreported by Barbeta et al. (2020) for potted saplings of European beech (Fagus sylvatica L.).

Inter-specific differences in the degree to which the isotopic composition of xylem water deviates from soil water have been observed in previous work. Gaines et al. (2016) found xylem water from oak (Quercus) and hickory (Carya) trees tended to be more depleted in heavy isotopes than that of Acer. Xylem water ${ }^{2} \mathrm{H}$ for deciduous (beech and oak) species in Switzerland was more depleted compared to spruce (Allen et al., 2019). Our results contrast with those of White and Smith (2015), who saw limited inter-specific differences in the isotopic composition of plant water for box elder (Acer negundo L.) or river birch (Betula nigra L.) at a given phenological stage in the foothills of the southern Appalachian Mountains. Inter-specific variations in xylem water isotopic composition and its temporal changes at PC-1 are likely not due to distinct environmental conditions for the different tree species, given the close proximity of the sampled trees and similar soil conditions under the tree canopies. 


\subsection{Potential drivers of plant-soil water isotopic differences}

Several factors have been suggested which might account for the observed differences between the isotopic compositions of xylem water and bulk soil water in PC-1. Some of these may be common to all studied tree species, while others cannot account for inter-specific differences in the temporal trajectory of xylem water isotopic composition during the study period.

\subsubsection{Errors in measuring xylem water composition}

We do not fully know what kind of vegetation water is mobilised by cryogenic extraction (the approach used here to obtain xylem water samples), although it is usually assumed to characterise xylem water (Tetzlaff et al., 2021). Millar et al. (2018) noted that cryogenic extraction resulted in more depleted xylem water ${ }^{2} \mathrm{H}$ in spring wheat compared to other extraction methods. However, such an experimental issue might be expected to influence measured xylem water isotopic compositions relatively consistently across species and seasons and does not readily account for the inter-specific differences in xylem water $\delta^{2} \mathrm{H}$ at PC- 1 . We have noted our previous work that found no significant difference between the isotopic composition of soil water determined by cryogenic extraction and the direct equilibration method (Tetzlaff et al., 2021), and others have found no consistent evidence that cryogenic extraction alters xylem water's isotopic values (Barbeta et al., 2015; Grossiord et al., 2017). Berry et al. (2017) suggested cavitation (air entry) during extraction of stem cores from trees and increasing time lags between extraction and sealing the sample allow evaporation that fractionates the remaining sample water. Given the rapid processing of xylem water samples at PC-1, the inter-specific and temporal variation in xylem water isotopic composition and its pronounced divergence from that of all other potential water sources, the displacement of xylem water from bulk soil water is likely not attributable to a methodological issue.

\subsubsection{Unsampled water sources}

The possibility that bulk soil water does not represent rootabsorbed water implies plants selectively access an isotopically fractionated portion of soil water (McCutcheon et al., 2017). However, soils in PC-1 at peak leaf out were very dry, while Ce xylem water lc-excess was much more negative than corresponding bulk soil water (Fig. 5). Presence of sufficient soil water with very negative lc-excess values that could both match the xylem water lc-excess and supply the tree's transpiration demand is unlikely under these circumstances. Trees may have accessed water held in bedrock fractures that may be isotopically distinct from mobile soil water (Oshun et al., 2016). However, bedrock in PC-1 appears to be relatively unfractured, making it difficult to envisage sufficient water held in fractures that could supply transpiration to a significant extent. This echoes Gaines et al. (2016), who saw little evidence that roots within or below fractured bedrock in central Pennsylvania were consistent major contributors to transpiration.

\subsubsection{Soil water content}

Evaristo et al. (2019) found differences between the isotopic compositions of plant water and low mobility soil matrix water to be greatest under drought conditions and least at the transition from drought to rewetting. The greatest differences between xylem water and bulk soil water isotopic compositions at PC-1 for Ce and He were generally at peak leaf out (Fig. 6) following a protracted decline in SWCs (Fig. 2); however, these differences persisted following soil rewetting. Barbeta et al. (2020) found soil water-plant water $\delta^{2} \mathrm{H}$ offsets increased with soil water content, whereas the smallest offsets at PC-1 were either at post-senescence 2015 (Ce) or pre-leaf out (He, Or, $\mathrm{Pw}$ ) when SWCs would be relatively large as shown by previous work in PC-1 (e.g. Devito and Dillon, 1993). Thus, the influence of soil water content on differences in xylem water-soil water isotopic composition is unclear and deserves further study.

\subsubsection{Storage effect}

Xylem water at a given time may be influenced by the isotopic composition of water taken up days or months beforehand (McCutcheon et al., 2017; Penna et al. 2018; Evaristo et al., 2019). Sprenger et al. (2018c) estimated median ages of total soil water storage in PC-1 ranging from 31 (25th percentile) to $74 \mathrm{~d}$ (75th percentile). This storage effect may assist in explaining the frequent distinction between xylem water and bulk soil water lc-excess for a given sampling period and is supported by partial $(\mathrm{He}, \mathrm{Pw})$ or complete (Or) overlap of the lc-excess of post-senescence 2015 soil water and pre-leaf out xylem water in 2016 (Fig. 7). However, Ce xylem water lc-excess was much more negative than postsenescence 2015 bulk soil water, suggesting this mechanism may differ in importance between tree species. Such a mechanism also fails to account for $\mathrm{Ce}$ and to some extent $\mathrm{Pw}$ lc-excess values that were much more negative than any bulk soil water (Figs. 3 and 5).

\subsubsection{Interactions with carbonates or other geochemical and organic constituents}

These include isotopic effects between soil water and cations/clay minerals (Oerter et al., 2014), organic matter (Orlowski et al., 2016) and rock-water interactions (Lin and Horita, 2016; Oshun et al., 2016) that differ for $\mathrm{H}$ and O. The potential for any or all of these processes to induce differences in xylem water isotopic composition relative to soil water at PC-1 is not known, although the low clay contents of PC-1 soils make significant isotopic effects with clay min- 
erals unlikely (Sprenger et al., 2018b). Regardless, it would be reasonable to expect that such processes would be similar in the soil water surrounding the different tree species. Thus, they do not easily explain inter-specific differences in the degree of isotopic displacement of xylem water from the LMWL and bulk soil water.

\subsubsection{Fractionation during water uptake}

There is increasing recognition that differences between xylem water and soil water isotopic compositions may result from isotopic fractionation induced by internal plant processes during water uptake (Berry et al., 2017). Ellsworth and Williams (2007) showed that 12 of 16 species of woody plants demonstrated $\mathrm{H}$ isotope fractionation at the soil-root interface, while Vargas et al. (2017) found plants discriminated against ${ }^{18} \mathrm{O}$ and ${ }^{2} \mathrm{H}$ during water uptake with differences between $\delta^{18} \mathrm{O}$ and $\delta^{2} \mathrm{H}$ in soil water relative to plant water increasing with transpiration water loss. This would lead to more negative $\delta^{18} \mathrm{O}$ and $\delta^{2} \mathrm{H}$ in plant water relative to soil water, as seen at PC-1. It also suggests the greatest differences between xylem water and soil water lc-excess would be at peak leaf out when PC-1 soils were at their driest (Fig. A1). This was the case for $\mathrm{Ce}$, which showed clear separation between soil and xylem water lc-excess at peak leaf out (Fig. 5). This also occurred at pre-senescence for Pw; however, there was overlap between soil water and xylem water lc-excess for Or and He. Thus, the potential for fractionation during water uptake may be a major cause of deviations between soil water and xylem water isotopic compositions and may differ between tree species in northern mixed forests.

\subsubsection{Fractionation following uptake}

Changes in the isotopic composition of xylem water relative to that of soil water have been attributed to such processes as xylem-phloem exchange during water stress (Cernusak et al., 2005; Bertrand et al., 2014), isotopic depletion of storage water in xylem tissue compared to water moving via conductive tissues (Barbeta et al., 2020), $\mathrm{H}$ fractionation when water movement in the tree occurs predominantly via symplastic rather than via apoplastic pathways (Lin and Sternberg, 1993; Ellsworth and Williams, 2007) and fractionation within the tree's leaves, which then impacts the isotopic composition of phloem sap (Farquhar et al., 2007). We are not able to assess influence of any of these processes on xylem water composition at PC-1. There is also the potential for evaporation through the tree's bark (Dawson and Ehleringer, 1991; Smith et al., 1997). Bowling et al. (2017) thought this could not explain evaporative enrichment of xylem water in their study given the large stems sampled and removal of bark from all stem samples, as was the case at PC-1. Nevertheless, the overlap between many xylem water samples and the range in evaporation lines originating from the most isotopically depleted snowmelt sample (Fig. 4) suggest that uptake of snowmelt water at the start of the growing season and subsequent evaporative enrichment of xylem water postuptake cannot be ruled out.

\subsubsection{Plant physiology, rooting behaviour and water use strategies}

White and Smith (2015) noted a divergence in xylem water $\delta^{2} \mathrm{H}$ between species from the beginning of the dormant period. This was similar to PC-1, where Or xylem water generally became more depleted moving from pre-leaf out to postsenescence 2016, while the reverse trend occurred for Ce, $\mathrm{Pw}$ and to a lesser extent He (Fig. 5). White and Smith (2015) suggested such divergence may be due to differing periods of inactivity for the two species they studied. This may be relevant to deciduous species such as Or that experiences leaf out and senescence and whose timing and intensity of water use may differ from that of coniferous species. Phillips and Ehleringer (1995) found evaporatively enriched stem water in big-toothed maple (Acer grandidentatum Nutt.) and Gambel's oak (Quercus gambelii) before leaf flush and saw stem water move closer to the LMWL at full leaf out. We found similar results for Or where lc-excess became less negative at peak leaf out relative to pre-leaf out, although the difference was not statistically significant (Fig. 5). Gaines et al. (2016) noted xylem water tended to be more depleted in heavy isotopes from larger trees compared to smaller ones. The reverse was the case at PC-1, where the smallest trees (Ce; Table 1) showed the most depleted xylem water ${ }^{2} \mathrm{H}$. Shallow soils overlying bedrock at PC-1 would likely constrain the ability of different tree species to develop marked contrasts in rooting architectures (e.g. deep tap roots for some species vs. shallow root networks for others). However, inter-specific differences in the rooting behaviour and water use strategies of trees studied at PC-1 are unknown. The issue of root activity is one of the most difficult dilemmas facing plant ecology and ecohydrology (Beyer et al., 2016). Inter-specific differences in plant water lc-excess may reflect variations in rooting characteristics and shifts in the depth of water uptake in response to changes in water availability (McCutcheon et al., 2017; Dubbert and Werner, 2019). This topic should be a focus of further work in northern forest landscapes.

Despite considering these manifold possible processes, the cause of isotopic distinction between xylem water and potential water sources remains unclear. Nevertheless, some mechanisms noted above (e.g. fractionation at the plant root, evaporation through the bark) are more plausible under conditions at PC-1 than others (e.g. xylem water accessing an unsampled source of water not reflected in bulk soil water isotope values, errors in determination of xylem water isotopic composition).

Regardless, our results provide novel insight into potential changes in hydroecological fluxes in northern mixed forests in response to hydroclimatic change. The landscape surrounding PC-1 in Ontario is projected to experience in- 
creases in summer temperatures above the 1971-2000 baseline of between 2 and $8^{\circ} \mathrm{C}$ (and presumably accompanying increases in evaporation) and decreases in summer rainfall of up to $25 \mathrm{~mm}$ for the 2071-2100 period (McDermid et al., 2015). The 2016 growing season was a particularly dry one; thus, the small SWCs and associated inter-specific differences in xylem water-bulk soil water isotopic relationships presented here may become typical of future conditions in this and similar northern forest landscapes across the Northern Hemisphere.

\section{Conclusion}

We examined the co-evolution of xylem water and bulk soil water isotopic compositions during the growing season for four tree species in a northern mixed forest. The major findings are as follows:

1. Bulk soil water isotopic composition showed similar temporal changes below the canopies of all tree species, with evaporative enrichment of near-surface soil water from pre-leaf out to peak leaf out followed by a return to values along the LMWL at post-senescence.

2. In contrast, xylem water isotopic composition showed inter-specific differences in both the degree of its displacement from the LMWL and bulk soil water and the temporal trajectory of its changes from pre-leaf out to post-senescence.
3. This trajectory differed between deciduous and coniferous species. Red oak xylem water experienced depletion in both ${ }^{2} \mathrm{H}$ and ${ }^{18} \mathrm{O}$ during the growing season, while conifer xylem water showed isotopic enrichment. This may be related to inter-specific variations in the timing and intensity of growing season water use in northern mixed forests and requires further study.

4. A review of possible reasons for distinctions between xylem water and soil water isotopic compositions for these tree species suggested that some mechanisms (e.g. fractionation at the tree root, evaporation through the bark) were more plausible than others (e.g. an unsampled source of water taken up during transpiration) when considered in the context of the study site's characteristics. Nevertheless, inter-specific differences in the degree to which these mechanisms may account for the varying relationships between xylem water and soil water may be related to the physiology, rooting behaviour and water use strategies of deciduous and coniferous trees. These should be explored in further research as we attempt to understand more fully how trees take up water during transpiration in order to predict their response to anticipated hydroclimatic changes in northern forest landscapes. 


\section{Appendix A}
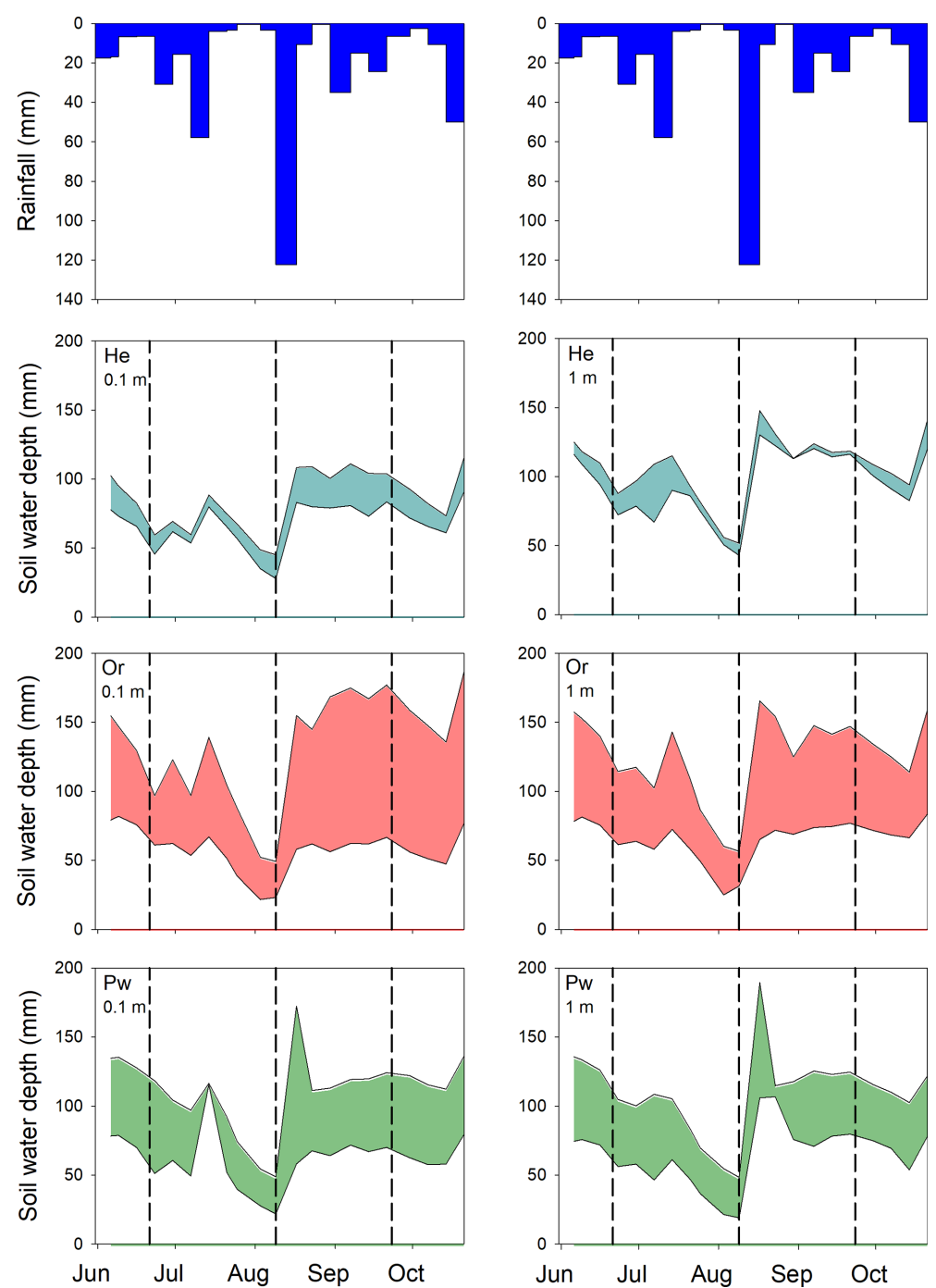

Figure A1. Rainfall depths and range of total soil water depths held in the upper $0.5 \mathrm{~m}$ of soil at 0.1 (left-hand panels) and $1 \mathrm{~m}$ (right-hand panels) from the bole of $\mathrm{He}$ (second row), Or (third row) and Pw (fourth row) trees during the 2016 growing season. Vertical dashed lines indicate the timing of post-leaf out, peak leaf out and pre-senescence sampling of xylem water and bulk soil water. 


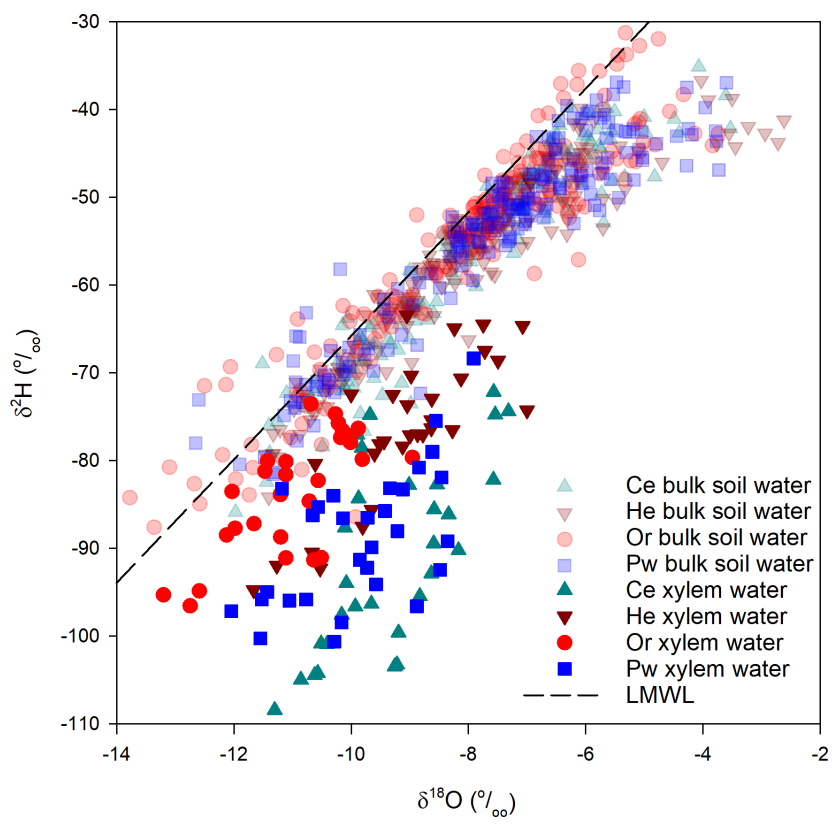

Figure A2. Isotopic composition of xylem water and bulk soil water (sampled at $5 \mathrm{~cm}$ intervals from the soil surface) for the sampled tree species. $\mathrm{Ce}$ - eastern white cedar, $\mathrm{He}$ - eastern hemlock, Or - red oak, Pw - eastern white pine, LMWL - local meteoric water line. 
Data availability. The underlying research data can be accessed at https://doi.org/10.5683/SP2/TGCHV6 (Buttle, 2020).

Author contributions. JRS and JMB designed the experiment, and JRS conducted the fieldwork and data analysis. JRS prepared the manuscript with contributions from all co-authors.

Competing interests. The authors declare that they have no conflict of interest.

Special issue statement. This article is part of the special issue "Water, isotope and solute fluxes in the soil-plant-atmosphere interface: investigations from the canopy to the root zone". It is not associated with a conference.

Acknowledgements. Thanks are expressed to the Dorset Environmental Research Centre for meteorological data, Carl Mitchell (University of Toronto Scarborough) for snowmelt lysimeter isotope data, Samantha Evans (Boise State University), Jeff McDonnell and Kim Janzen (University of Saskatchewan) for isotopic analyses, Robert Monico and Ciara Cooke for field assistance and to the editor (Natalie Orlowski) and two anonymous reviewers for constructive comments on an earlier version of this paper.

Financial support. This research has been supported by the Natural Sciences and Engineering Research Council of Canada (grant no. 2015-06116) and the European Research Council, FP7 Ideas: European Research Council (grant no. VEWA (335910)).

Review statement. This paper was edited by Natalie Orlowski and reviewed by two anonymous referees.

\section{References}

Allen, R. G., Periera, L. S., Raes, D., and Smith, M.: Crop evapotranspiration - Guidelines for computing crop water requirements, FAO Irrigation and Drainage Paper 56, FAO, Rome, 1998.

Allen, S. T., Kirchner, J. W., Braun, S., Siegwolf, R. T. W., and Goldsmith, G. R.: Seasonal origins of soil water used by trees, Hydrol. Earth Syst. Sci., 23, 1199-1210, https://doi.org/10.5194/hess-23-1199-2019, 2019.

Araguás-Araguás, L., Rozanski, K., Gonfiantini, R., and Louvat, D.: Isotope effects accompanying vacuum extraction of soil water for stable isotope analyses, J. Hydrol., 168, 159-171, 1995.

Barbeta, A., Mejía-Chang, M., Ogaya, R., Voltas, J., Dawson, T. E., and Peñuelas, J.: The combined effects of a long-term experimental drought and an extreme drought on the use of plantwater sources in a Mediterranean forest, Global Change Biol., 21, 1213-1225, 2015.

Barbeta, A., Gimeno, T. E., Clavé, L., Fréjaville, B., Jones, S. P., Delvigne, C., Wingate, L., and Ogée, J.: An explanation for the isotopic offset between soil and stem water in a temperate tree species, New Phytolol., 227, 766-779, 2020.

Benettin, P., Volkmann, T. H. M., von Freyberg, J., Frentress, J., Penna, D., Dawson, T. E., and Kirchner, J. W.: Effects of climatic seasonality on the isotopic composition of evaporating soil waters, Hydrol. Earth Syst. Sci., 22, 2881-2890, https://doi.org/10.5194/hess-22-2881-2018, 2018.

Berry, Z.C., Evaristo, J., Moore, G., Poca, M., Steppe, K., Verrot, L., Asbjornsen, H., Borma, L.S., Bretfeld, M., HervéFernández, P., Seyfried, M., Schwendenmann, L., Sinacore, K., De Wisperlaere, L., and McDonnell, J.: The two water worlds hypothesis: Addressing multiple working hypotheses and proposing a way forward, Ecohydrology, 11, e1843, https://doi.org/10.1002/eco.1843, 2017.

Bertrand, G., Masini, J., Goldscheider, N., Meeks, J., Lavastre, V., Celle-Jeanton, H., Gobat, J. M., and Hunkeler, D.: Determination of spatiotemporal variability of tree water uptake using stable isotopes $\left(\delta^{18} \mathrm{O}, \delta^{2} \mathrm{H}\right)$ in an alluvial system supplied by a highaltitude watershed, Pfyn forest, Switzerland, Ecohydrology, 7, 319-333, 2014.

Beyer, M., Koeniger, O., Gaj, M., Hamutoko, J. T., Wanke, H., and Himmelsbach, T.: A deuterium-based labeling technique for the investigation of rooting depths, water uptake dynamics and unsaturated zone water transport in semiarid environments, J. Hydrol., 533, 627-643, 2016.

Birks, S. S. and Gibson, J. J.: Isotope hydrology research in Canada, 2003-2007, Can. Water Resour. J., 34, 163-176, 2009.

Bowling, D. R., Schulze, E. S., and Hall, S. J.: Revisiting streamside trees that do not use stream water: Can the two water worlds hypothesis and snowpack isotopic effects explain a missing water source?, Ecohydrology, 10, e1771, https://doi.org/10.1002/eco.1771, 2017.

Brinkmann, N., Eugster, W., Buchmann, N., and Kahmen, A.: Species-specific differences in water uptake depth of mature temperate trees vary with water availability in the soil, Plant Biol., 21, 71-81, 2019.

Brooks, J. R., Barnard, H. R., Coulombe, R., and McDonnell, J. J.: Ecohydrological separation of water between trees and streams in a Mediterranean climate, Nat. Geosci., 3, 100-104, 2010.

Buttle, J.: Snelgrove et al HESS 2020 submission, Scholars Portal Dataverse, https://doi.org/10.5683/SP2/TGCHV6, 2020.

Buttle, J. M. and House, D. A.: Spatial variability of saturated hydraulic conductivity in shallow macroporous soils in a forested basin, J. Hydrol., 203, 127-142, 1997.

Carey, S. K., Tetzlaff, D., Seibert, J., Soulsby, C., Buttle, J., Laudon, H., McDonnell, J., McGuire, K., Caissie, D., Shanley, J., Kennedy, M., Devito, K., and Pomeroy, J. W.: Intercomparison of hydro-climatic regimes across northern catchments: synchronicity, resistance and resilience, Hydrol. Process., 24, 3591-3602, 2010.

Carey, S. K., Tetzlaff, D., Buttle, J., Laudon, H., McDonnell, J., McGuire, K., Seibert, J., Soulsby, C., and Shanley, J.: Use of color maps and wavelet coherence to discern seasonal and inter annual climate influences on streamflow variability in northern catchments, Water Resour. Res., 49, 6194-6207, 2013.

Cernusak, L. A., Farquhar, G. D., and Pate, J. S.: Environmental and physiological controls over oxygen and carbon isotope composition of Tasmanian blue gum, Eucalyptus globulus, Tree Physiol., 25, 129-146, 2005. 
Coplen, T. B., Hopple, J. A., Bohlke, J. K., Peiser, H. S., Rieder, S. E., Krouse, H. R., Rosman, K. J. R., Ding, T., Voche, R. D., Revesz, K., Lamberty, A., Taylor, P., and De Bievre, P.: Compilation of minimum and maximum isotope ratios of selected elements in naturally occurring terrestrial materials and reagents, Water-Resources Investigations Report 01-4222, US Geological Survey, Reston, Virginia, 98 pp., 2002.

Dawson, T. E. and Ehleringer, J. R.: Streamside trees that do not use streamwater, Nature, 350, 335-372, 1991.

Devito, K. J. and Dillon, P.: The influence of hydrologic conditions and peat oxia on the phosphorus and nitrogen dynamics of a conifer swamp, Water Resour. Res., 29, 2675-2685, 1993.

Dubbert, M. and Werner, C.: Water fluxes mediated by vegetation: emerging isotopic insights at the soil and atmosphere interfaces, New Phytol., 221, 1754-1763, 2019.

Ellsworth, P. Z. and Williams, D. G.: Hydrogen isotope fractionation during water uptake by woody xerophytes, Plant Soil, 291, 93-107, 2007.

Evaristo, J., Jasechko, S., and McDonnell, J. J.: Global separation of plant transpiration from groundwater and streamflow, Nature, 525, 91-96, 2015.

Evaristo, J., Kim, K., van Haren, J., Pangle, L. A., Harman, C. J., Troch, P. A., and McDonnell, J. J.: Characterizing the fluxes and age distribution of soil water, plant water, and deep percolation in a model tropical ecosystem, Water Resour. Res., 55, 3307-3327, https://doi.org/10.1029/2018WR023265, 2019.

Farquhar, G. D., Cernusak, L. A., and Barnes, B.: Heavy water fractionation during transpiration, Plant Physiol., 143, 11-18, 2007.

Gaines, K. P., Stanley, J. W., Meinzer, F. C., McCulloh, K. A., Woodruff, D. R., Chen, W., Adams, T. S., Lin, H., and Eissenstat, D. M.: Reliance on shallow soil water in a mixed-hardwood forest in central Pennsylvania, Tree Physiol., 36, 444-458, 2016.

Geris, J., Tetzlaff, D., McDonnell, J., Anderson, J., Paton, G., and Soulsby, C.: Ecohydrological separation in wet, low energy northern environments? A preliminary assessment using different soil water extraction techniques, Hydrol. Process., 29, 5139 5152, 2015.

Goldsmith, G. R., Muñoz-Villers, L. E., Holwerda, F., McDonnell, J. J., Asbjornsen, H., and Dawson, T. E.: Stable isotopes reveal linkages among ecohydrological processes in a seasonally dry tropical montane cloud forest, Ecohydrology, 5, 779-790, 2012.

Grüning, M., Lutz, H. O., Roller-Lutz, Z., Gourcy, L., and Pöltenstein, L.: A simple rain collector preventing water reevaporation for $\delta^{18} \mathrm{O}$ and $\delta^{2} \mathrm{H}$ analysis of cumulative precipitation samples, J. Hydrol., 448-449, 195-200, 2012.

Grossiord, C., Sevanto, S., Dawson, T. E., Adams, H. D., Collins, A. D., Dickman, L. T., Newman, B. D., Stockton, E. A., and McDowell, N. G.: Warming combined with more extreme precipitation regimes modifies the water source used by trees, New Phytol., 213, 584-596, 2017.

Guswa, A. J., Tetzlaff. D., Selker, J. S., Carlyle-Moses, D. E., Boyer, E. W., Bruen, M., Cayuela, C., Creed, I. F., van de Giesen, N., Grasso, D., Hannah, D. M., Hudson, J. E., Hudson, S. A., Iida, S., Jackson, R. B., Katul, G. G., Kumagai, T., Llorens, P., Lopes Ribeiro, F., Michalzik, B., Nanko, K., Oster, C., Pataki, D. E., Peters, C. A., Rinaldo, A., Sanchez Carretero, D., Trifunovic, B., Zalewski, M., Haagsma, M., and Levia, D. F.: Advancing ecohydrology in the 21 st century: A convergence of opportuni- ties, Ecohydrology, 13, e2208, https://doi.org/10.1002/eco.2208, 2020.

Hartmann, D. L, Klein Tank, A. M. G, Rusticucci, M, Alexander, L. V, Brönnimann, S, Charabi, Y., Dentener, F. J., Dlugokencky, E. J., Easterling, D. R., Kaplan, A., Soden, B. J., Thorne, P. W., Wild, M., and Zhai, P. M.: Observations: atmosphere and surface, in: Climate Change 2013: The Physical Science Basis: Contribution of Working Group I to the Fifth Assessment Report of the Intergovernmental Panel on Climate Change, edited by: Stocker, T. F., Qin, D., Plattner, G.-K., Tignor, M., Allen, S. K., Boschung, J., Nauels, A., Xia, Y., Bex, V., and Midgley, P. M., Cambridge University Press, Cambridge, UK and New York, USA, 159-254, 2013.

Hendry, M. J., Schmeling, E., Wassenaar, L. I., Barbour, S. L., and Pratt, D.: Determining the stable isotope composition of pore water from saturated and unsaturated zone core: improvements to the direct vapour equilibration laser spectrometry method, Hydrol. Earth Syst. Sci., 19, 4427-4440, https://doi.org/10.5194/hess-19-4427-2015, 2015.

Hervé-Fernández, P., Oyarzún, C., Brumbt, C., Huygens, D., Bodé, S., Verhoest, N. E. C., and Boeckx, P.: Assessing the 'two water worlds' hypothesis and water sources for native and exotic evergreen species in south-central Chile, Hydrol. Process., 30, 4227-4241, 2016.

Klaus, J., McDonnell, J. J., Jackson, C. R., Du, E., and Griffiths, N. A.: Where does streamwater come from in low-relief forested watersheds? A dual-isotope approach, Hydrol. Earth Syst. Sci., 19, 125-135, https://doi.org/10.5194/hess-19-125-2015, 2015.

Knighton, J., Souter-Kline, V., Volkma, T., Troch, P. A., Kim, M., Harman, C., Morris, C., Buchanan, B., and Walter, M. T.: Seasonal and topographic variations in ecohydrological separation within a small, temperate, snow-influenced catchment, Water Resour. Res., 55, 6417-6435, 2019.

Koeniger, P., Marshall, J. D., Link, T., and Mulch, A.: An inexpensive, fast, and reliable method for vacuum extraction of soil and plant water for stable isotope analyses by mass spectrometry, Rapid Commun. Mass Spectrom., 25, 3041-3048, 2011.

Landwehr, J. M. and Coplen, T. B.: Line-conditioned excess: a new method for characterizing stable hydrogen and oxygen isotope ratios in hydrologic systems, in: International Conference on Isotopes in Environmental Studies, Aquatic Forum 2004, IAEACSP-26, International Atomic Energy Agency, Vienna, 132-135, 2006.

Lane, D., McCarter, C. P. R., Richardson, M., McConnell, C., Field, T., Yao, H., Arhonditsis, G., and Mitchell, C. P. J.: Wetlands and low-gradient topography are associated with longer hydrologic transit times in Precambrian Shield headwater catchments, Hydrol. Process., 34, 598-614, 2020.

Laudon, H., Spence, C., Buttle, J., Carey, S. K., McDonnell, J., McNamara, J. P., Soulsby, C., and Tetzlaff, D.: Preserve northern latitude catchment studies, Nat. Geosci., 10, 324-325, 2017.

Lin, G. and Sternberg, L. S. L.: Hydrogen isotopic fractionation by plant roots during water uptake in coastal wetland plants, in: Stable Isotopes and Plant Carbon-Water Relations, edited by: Ehleringer, J. R., Hall, A. E., and Farquhar, G. D., Academic Press Inc., New York, USA, 497-510, 1993.

Lin, Y. and Horita, J.: An experimental study on isotope fractionation in a mesoporous silica-water system with implications for 
vadose-zone hydrology, Geochim. Cosmochim. Ac., 184, 257271, https://doi.org/10.1016/j.gca.2016.04.029, 2016.

Liu, Y., Fang, Y., Hu, H., Tian, F., Dong, Z., and Khan, M. Y. A.: Ecohydrological separation hypothesis: review and prospect, Water, 12, 2077, https://doi.org/10.3390/w12082077, 2020.

McCutcheon, R. J., McNamara, J. P., Kohn, M. J., and Evans, S. L.: An evaluation of the ecohydrological separation hypothesis in a semiarid catchment, Hydrol. Process., 31, 783-799, 2017.

McDermid, J., Fera, S., and Hogg, A.: Climate change projections for Ontario: An updated synthesis for policymakers and planners, Climate Change Research Report CCRR-44, Ontario Ministry of Natural Resources and Forestry, Science and Research Branch, Peterborough, Ontario, 39 pp., 2015.

McDonnell, J. J.: The two water worlds hypothesis: ecohydrological separation of water between streams and trees?, Wiley Interdisciplin. Rev.: Water, 1, 323-329, 2014.

Millar, C., Pratt, D., Schneider, D. J., and McDonnell, J. J.: A comparison of extraction systems for plant water stable isotope analysis, Rapid Commun. Mass Spectrom., 32, 1031-1044, 2018.

Myers-Smith, I. H., Thomas, H. J., and Bjorkman, A. D.: Plant traits inform predictions of tundra responses to global change, New Phytol., 221, 1742-1748, 2019.

Neary, A. J., Mistray, E., and Vanderstar, L.: Sulphate relationships in some central Ontario forest soils, Can. J. Soil Sci., 67, 341$352,1987$.

Oerter, E., Finstad, K., Schaefer, J., Goldsmith, G. R., Dawson, T., and Amundson, R.: Oxygen isotope fractionation effects in soil water via interaction with cations $(\mathrm{Mg}, \mathrm{Ca}, \mathrm{K}, \mathrm{Na})$ adsorbed to phyllosilicate clay minerals, J. Hydrol., 515, 1-9, 2014.

Orlowski, N., Breuer, L., and McDonnell, J. J.: Critical issues with cryogenic extraction of soil water for stable isotope analysis, Ecohydrology, 9, 3-10, 2016.

Orlowski, N., Breuer, L., Angeli, N., Boeckx, P., Brumbt, C., Cook, C. S., Dubbert, M., Dyckmans, J., Gallagher, B., Gralher, B., Herbstritt, B., Hervé-Fernández, P., Hissler, C., Koeniger, P., Legout, A., Macdonald, C. J., Oyarzún, C., Redelstein, R., Seidler, C., Siegwolf, R., Stumpp, C., Thomsen, S., Weiler, M., Werner, C., and McDonnell, J. J.: Inter-laboratory comparison of cryogenic water extraction systems for stable isotope analysis of soil water, Hydrol. Earth Syst. Sci., 22, 3619-3637, https://doi.org/10.5194/hess-22-3619-2018, 2018.

Oshun, J., Dietrich, W. E., Dawson, T. E., and Fung, I.: Dynamic, structured heterogeneity of water isotopes inside hillslopes, Water Resour. Res., 52, 164-189, 2016.

Penna, D., Hopp, L., Scandellari, F., Allen, S. T., Benettin, P., Beyer, M., Geris, J., Klaus, J., Marshall, J. D., Schwendenmann, L., Volkmann, T. H. M., von Freyberg, J., Amin, A., Ceperley, N., Engel, M., Frentress, J., Giambastiani, Y., McDonnell, J. J., Zuecco, G., Llorens, P., Siegwolf, R. T. W., Dawson, T. E., and Kirchner, J. W.: Ideas and perspectives: Tracing terrestrial ecosystem water fluxes using hydrogen and oxygen stable isotopes -challenges and opportunities from an interdisciplinary perspective, Biogeosciences, 15, 6399-6415, https://doi.org/10.5194/bg-15-6399-2018, 2018.

Phillips, S. L. and Ehleringer, J. R.: Limited uptake of summer precipitation by bigtooth maple (Acer grandidentatum Nutt) and Gambel's oak (Quereus gambelii Nutt), Trees, 9, 214-219, 1995.

R Core Team: R: A Language and Environment for Statistical Computing [Internet], R Foundation for Statistical Computing, Vi- enna, Austria, available at: https://www.R-project.org (last access: June 2020), 2019.

Retzlaff, W. A., Blaisdell, G. K., and Topa, M. A.: Seasonal changes in water source of four families of loblolly pine (Pinus taeda L.), Trees, 15, 154-162, 2001.

Smith, D. M., Jarvis, P. G., and Odongo, J. C. W.: Sources of water used by trees and millet in Sahelian windbreak systems, J. Hydrol., 198, 140-153, 1997.

Smith, T. J., McNamara, J. P., Flores, A. N., Gribb, M. M., Aishlin, P. S., and Benner, S. G.: Limited soil storage capacity constrains upland benefits of winter snowpack, Hydrol. Process., 25, 38583865, 2011.

Snelgrove, J., Buttle, J. M., and Tetzlaff, D. E.: Importance of rainfall partitioning in a northern mixed forest canopy for soil water isotopic signatures in ecohydrological studies, Hydrol. Process., 34, 284-302, 2019.

Sprenger, M. and Allen, S. T.: What ecohydrologic separation is and where can we go with it, Water Resour. Res., 56, e2020WR027238, https://doi.org/10.1029/2020WR027238, 2020.

Sprenger, M., Tetzlaff, D., Buttle, J., Carey, S., McNamara, J., Laudon, H., Shatilla, N., and Soulsby, C.: Storage, mixing and fluxes of water in the critical zone across northern environments inferred by stable isotopes of soil water, Hydrol. Process., 32, 1732-1737, 2018a.

Sprenger, M., Tetzlaff, D., Buttle, J., Laudon, H., Leistert, H., Mitchell, C. P. J., Snelgrove, J., Weiler, M., and Soulsby, C.: Measuring and modeling stable isotopes of mobile and bulk soil water, Vadose Zone J., 17, 170149, https://doi.org/10.2136/vzj2017.08.0149, 2018b.

Sprenger, M., Tetzlaff, D., Buttle, J., Laudon, H., and Soulsby, C.: Water ages in the critical zone of long-term experimental sites in northern latitudes, Hydrol. Earth Syst. Sci., 22, 3965-3981, https://doi.org/10.5194/hess-22-3965-2018, 2018c.

Tetzlaff, D., Buttle, J. M., Carey, S. K., McGuire, K., Laudon, H., and Soulsby, C.: Tracer-based assessment of flow paths, storage and runoff generation in northern catchments: a review, Hydrol. Process., 29, 3475-3490, 2015.

Tetzlaff, D., Buttle, J. M., Carey, S. K., Kohn, M., Laudon, H., McNamara, J. P., Smith, A., Sprenger, M., and Soulsby, C.: Stable isotopes of water reveal differences in plant - soil water relationships across northern environments, Hydrol. Process., 35, e14023, https://doi.org/10.1002/hyp.14023, 2021.

Vargas, A. I., Schaffer, B., Yuhong, L., and Sternberg, L. S. L.: Testing plant use of mobile vs immobile soil water sources using stable isotope experiments, New Phytol., 215, 582-594, 2017.

Watmough, S. A., Aherne, J., Eimers, M. C., and Dillon, P. J.: Acidification at Plastic Lake, Ontario: Has 20 years made a difference?, Water Air Soil Poll.: Focus, 7, 301-306, 2007.

Wels, C., Cornett, R. J., and LaZerte, B. D.: Groundwater and wetlands contributions to stream acidification: An isotopic analysis, Water Resour. Res., 26, 2993-3003, 1990.

White, J. C. and Smith, W. K.: Seasonal variation in water sources of the riparian tree species Acer negundo and Betula nigra, southern Appalachian foothills, USA, Botany, 93, 519-528, 2015.

Zhao, P., Tang, X., Zhao, P., Wang, C., and Tang, J.: Identifying the water source for subsurface flow with deuterium and oxygen18 isotopes of soil water collected from tension lysimeters and cores, J. Hydrol., 503, 1-10, 2013. 